\title{
PENGIRIMAN DATA KOORDINAT GLOBAL POSITION SYSTEM (GPS) PADA DRONE DENGAN MEMANFAATKAN JARINGAN INTERNET
}

\author{
Hero Wintolo \\ Program Studi Teknik Informatika \\ Sekolah Tinggi Teknologi Adisutjipto Yogyakarta \\ Email: herowintolo@stta.ac.id \\ Anggraini Kusumaningrum \\ Program Studi Teknik Informatika \\ Sekolah Tinggi Teknologi Adisutjipto Yogyakarta \\ Reza Aditya \\ Program Studi Teknik Informatika \\ Sekolah Tinggi Teknologi Adisutjipto Yogyakarta
}

\begin{abstract}
ABSTRAK
Drone merupakan salah satu teknologi canggih yang berupa kendaraan udara, drone yang digunakan dalam penelitian ini adalah Drone Syma X8HG dengan pengendalianya menggunakan remote control. Drone yang dikendalikan menggunakan remote memiliki keterbatasan sinyal. Sinyal yang digunakan bersumber dari jaringan WI-FI sehingga jarak jangkauan terbang drone terbatas. Layanan internet dari provider telekomunikasi belum bisa dimanfaatkan oleh drone karena fasilitas pada drone belum bisa terhubung pada jaringan tersebut. Agar data GPS dapat diambil dan dikirimkan melalui jaringan internet maka pada penelitian ini drone akan menerbangkan smartphone yang memiliki fasilitas GPS yang digunakan untuk mengirimkan data ke web server dan menampilkannya pada web. Hasil penelitian menunjukan bahwa titik koordinat atau lokasi pada smartphone yang diterbangkan oleh drone berhasil mengirimkan data latitude dan longitude melalui jaringan internet dan menampilkannya dalam bentuk Maps pada web.
\end{abstract}

Kata kunci: drone; remote; global position system (gps); lokasi; maps; koordinat; jaringan internet.

\begin{abstract}
Drone is one of the advanced technologies in the form of air vehicles, the drones used in this study are Syma X8HG Drones with controls using a remote control. Drones that are controlled using a remote have limited signal. The signal used is sourced from the WI-FI network so that the distance of the drone's flight range is limited. Internet services from telecommunications providers cannot be utilized by drones because the facilities on the drone cannot be connected to the network. In order for GPS data to be retrieved and sent via the internet network, in this study the drone will fly a smartphone that has GPS facilities that are used to send data to the web server and display it on the web. The results showed that the coordinates or location of a smartphone flown by a drone managed to send latitude and longitude data through the internet network and display it in the form of Maps on the web.
\end{abstract}

Keywords: drone; remote; global position system (gps); location; maps; coordinates; internet network.

\section{PENDAHULUAN}

Drone merupakan salah satu teknologi canggih yang berupa kendaraan udara. Bentuknya tersebut menyerupai pesawat terbang atau helikopter yang dapat dikendalikan dengan remote control dan tanpa remote control, memiliki bentuk yang lebih kecil dibandingkan dengan Unmanned Aerial Vehicle (UAV). Drone saat ini sudah banyak dibekali dengan Global Position System (GPS). Fungsi GPS pada drone digunakan untuk mengawali dan mengakhiri penerbangan sesuai dengan koordinat yang dimasukan oleh pengguna drone. Perubahan data koordinat dari awal hingga tujuan berakhirnya drone terbang tersimpan didalam drone, sehingga saat membutuhkannya kita harus mengambilnya dari drone tersebut, dalam keadaan tidak terbang, hal ini menjadi kendala dari sisi waktu yang digunakan untuk mendapatkan data GPS secepatnya. Drone yang digunakan dalam penelitian ini sama dengan penelitian sebelumnya[1,2] yang memanfaatkan drone tersebut membawa beban smartphone yang memiliki fasilitas kamera yang 
hasil pengambilan gambarnya dikirimkan melalui web server ke komputer agar jarak jangkauan terbangnya lebih tinggi dan jauh.

Sebelum fasilitas GPS ada pada smartphone atau handphone, pelacakan terhadap sebuah obyek baik di udara atau di darat menggunakan peralatan yang dirakit sendiri[2]. Setelah teknologi GPS diterapkan pada peralatan smartphone atau handphone maka pencarian obyek dapat memanfaatkan peralatan tersebut dengan mengintegrasikannya dengan Google Map dapat digunakan untuk mencari tempat ibadah[3], Anjungan Tunai Mandiri[4], informasi pariwisata[5], dan industri bordir[6].

Drone dapat terbang dengan cara dikendalikan menggunakan remote ataupun tanpa remote seperti drone yang menggunakan GPS. Bagi drone yang dikendalikan menggunakan remote memiliki keterbatasan sinyal yang digunakan untuk melakukan proses remote. Sinyal yang digunakan untuk mengendalikan drone menggunakan remote bersumber dari jaringan Wi-Fi sehingga jarak jangkauan terbang sangat dipengaruhi oleh sinyal Wi-Fi tersebut, keterbatasan sinyal Wi-Fi dapat diatasi dengan jaringan internet yang tersedia dari provider telekomunikasi. Layanan internet dari provider telekomunikasi belum bisa dimanfaatkan oleh drone karena fasilitas yang ada pada drone belum bisa digunakan untuk terhubung pada jaringan tersebut. Agar data GPS dapat diambil dan dikirimkan melalui jaringan internet maka pada penelitian ini drone akan membawa atau menerbangkan smartphone yang memiliki fasilitas GPS yang digunakan untuk mengirimkan data ke web server pada setiap pergerakan dari drone terebut.

\section{METODOLOGI PENELITIAN}

\subsection{Alat dan Bahan}

Beberapa kebutuhan perangkat keras dan perangkat lunak yang digunakan dalam penelitian ini adalah:
a) Komputer
b) Smartphone
c) Drone Syma $\mathrm{X} 8 \mathrm{HG}$
d) Internet

\subsection{Perancangan Desain Jaringan Komputer}

Skema pengambilan data koordinat pada Drone Syma X8HG yaitu Drone Syma X8HG, dapat dilihat pada gambar 1, berfungsi untuk menerbangkan sebuah smartphone Android yang memiliki fasilitas GPS dan memiliki koneksi jaringan internet. Setelah itu smartphone berfungsi untuk mengrim data koordinat lokasi secara real-time melalui jaringan internet. Internet ini berfungsi sebagai jalur pengiriman data dari smartphone ke web server. Selanjutnya web server berfungsi untuk menyimpan data koordinat yang sudah diterima dari smartphone mealui jaringan internet, dan website berfungsi untuk mengambil data koordinat dari web server melalui jaringan internet serta menampilkan data yang sudah diambil web server dalam bentuk tabel dan google map.

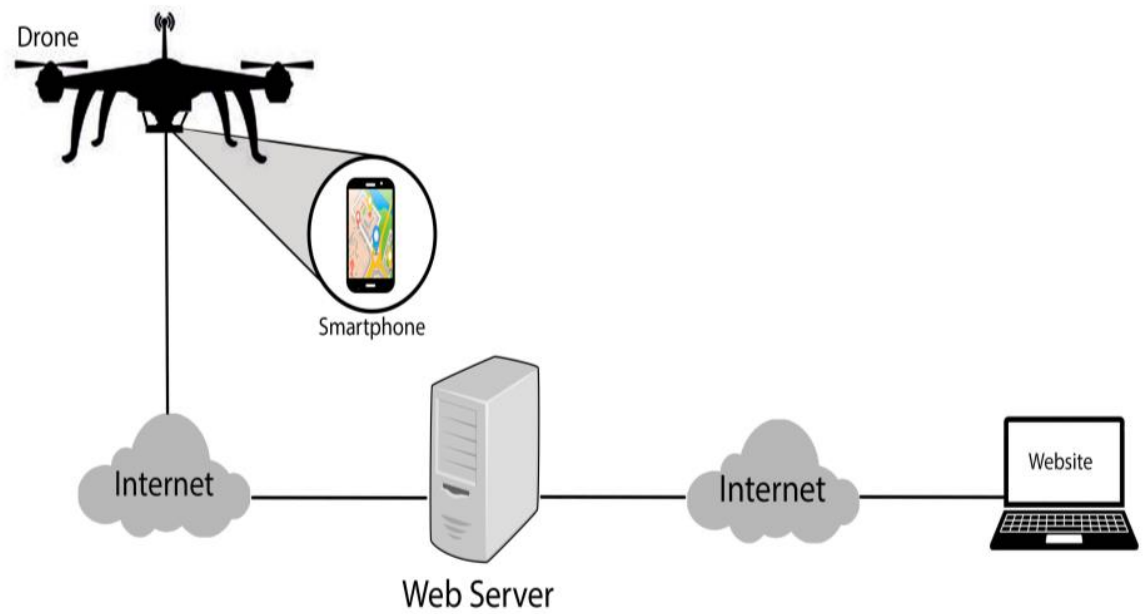

Gambar 1. Skema Pengambilan Data Koordinat pada Drone Syma X8HG 


\subsection{Use Case Diagram pada Android}

Proses perancangan perangkat lunak yang digunakan pada smartphone pada penelitian ini menggunakan metode use case diagram yang dapat dilihat pada gambar 2. Gambar ini merupakan use case diagram pada Android mulai dari proses user membuka atau mengaktifkan aplikasi kemudian akan otomatis server akan berjalan ketika aplikasi pada smartphone terkoneksi dengan internet.

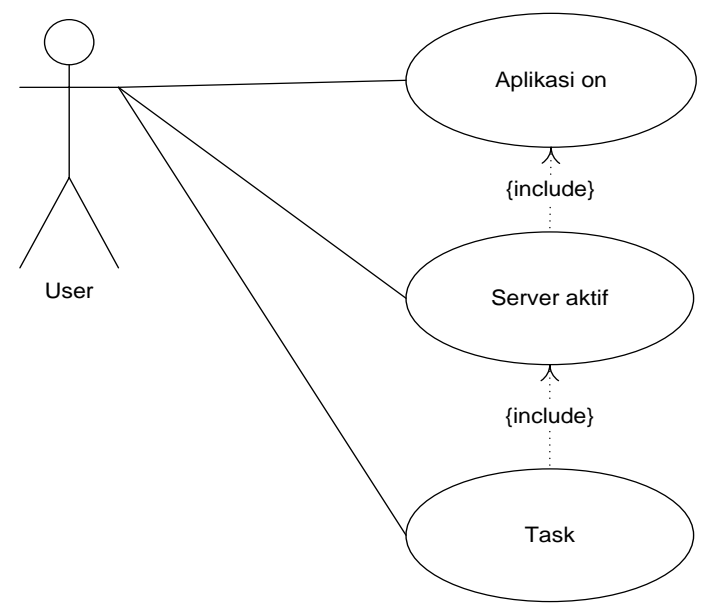

Gambar 2. Use Case Diagram pada Android

\subsection{Use Case Diagram pada Web}

Pada sisi komputer server yang akan menerima data dari drone, dirancang sebuah peragkat lunak dengan diagram case dapat dilihat pada gambar 3. Gambar ini merupakan use case diagram pada web dari proses user pengambilan lokasi dari web ke smartphone yang ada pada Drone Syma X8HG. Berikut penjelasan prosesnya:

a) User melakukan proses pengambilan data koordinat lokasi dari web ke smartphone yang diterbangkan oleh Drone Syma X8HG. Proses proses pengambilan data koordinat lokasi sudah saling terhubung antar web, smartphone dan server melalui jaringan internet.

b) Data koordinat lokasi yang sudah diambil melalui web sudah tersimpan dalam database server, dan user dapat melihat hasil data koordinat lokasi serta menghapusnya dari tabel data yang ada pada web.

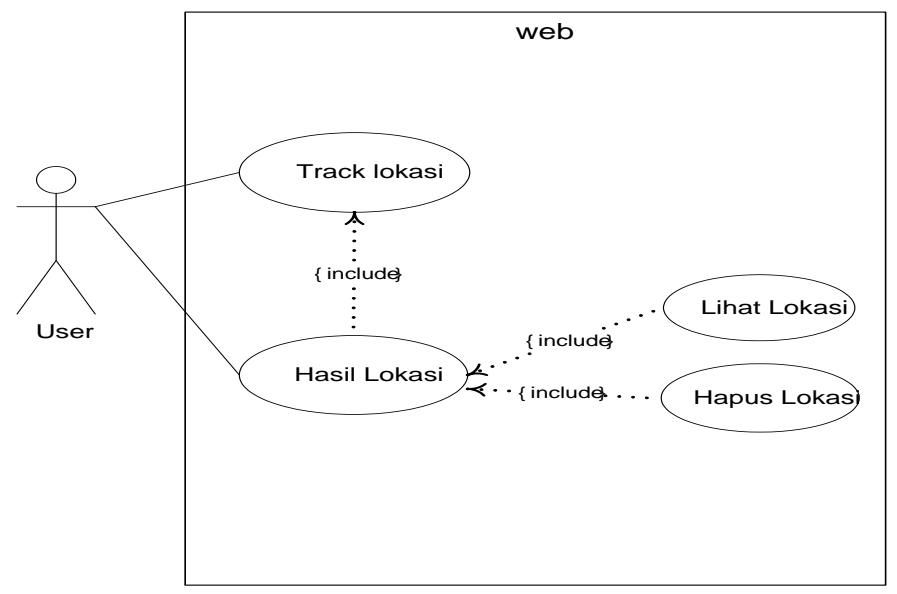

Gambar 3. Use Case Diagram pada Web

\subsection{Diagram Alir (Flowchart) pada Web}

Perancangan flowchart untuk proses jalannya sebuah program. User melakukan proses menjalankan web, kemudian membuka web. Setelah terbuka akan muncul tampilan menu utama, jika pengguna ingin mengambil data koordinat lokasi pilih track lokasi dan jika tidak ingin mengambil 
koordinat lokasi, maka web akan tetap ditampilan menu utama. Flowchart pada Web dapat dilihat pada gambar 4 .

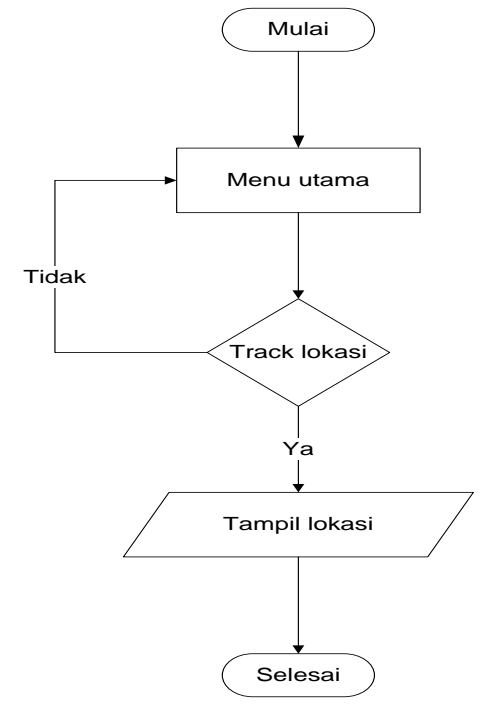

Gambar 4. Flowchart pada Web

\section{HASIL DAN PEMBAHASAN}

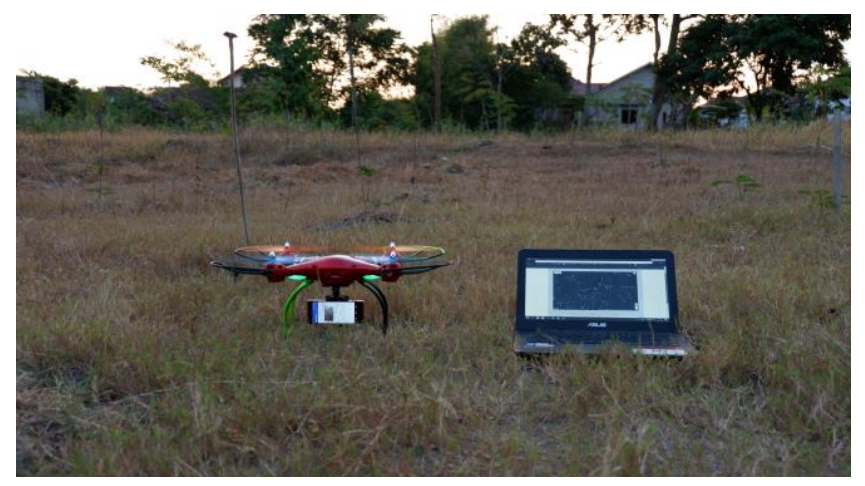

Gambar 5. Foto Drone Syma X8HG Belum Diterbangkan

Drone Syma X8HG dalam posisi aktif yang membawa smartphone Sony D5803, dapat dilihat pada gambar5, yang sudah diinstall aplikasi Remote Drone serta mempunyai koneksi internet pada smartphone Sony D5803 tersebut dan posisi laptop yang sudah aktif sekaligus membuka web Remote Drone untuk proses pengambilan data koordinat lokasi. Pengujian Drone Syma X8HG saat Terbang Vertikal dilakukan untuk mendapatkan data latitude dan longitude dari Drone Syma X8HG yang terbang secara vertikal dengan ketinggian 1 meter, 2 meter, dan diatas 2 meter yang dikirimkan melalui jaringan internet menggunakan provider Telkomsel yang ada pada smartphone Sony D5803, dan provider Telkomsel pada laptop. Hasil ini dapat dilihat pada Tabel 1.

Tabel 1 Drone Syma X8HG saat terbang vertikal

\begin{tabular}{llllll}
\hline No & Ketinggian & Waktu dikirim & Waktu diterima & Latitude & Longitude \\
\hline 1 & 1 meter & $11: 28: 30$ & $11: 28: 41$ & -7.7976216 & 110.4184385 \\
2 & 2 meter & $11: 28: 51$ & $11: 29: 02$ & -7.7976218 & 110.4184389 \\
3 & 4 meter & $11: 29: 39$ & $11: 29: 50$ & -7.7976211 & 110.4184384 \\
\hline
\end{tabular}

Pada Tabel 1 yaitu Drone Syma X8HG diterbangkan secara vertikal dengan ketinggian yang berbeda-beda mulai 1 meter, 2 meter, dan 4 meter. Pengukuran ketinggian ini menggunakan pipa paralon pvc yang dibuat dengan 3 ukuran ketinggian. Dari hasil tersebut terlihat bahwa: 
a) Baris ke 1 Drone Syma X8HG diterbangkan dengan ketinggian sekitar 1 meter diatas permukaan tanah yang mempunyai data yaitu waktu dikirim $=11: 28: 30$, waktu diterima $=11: 28: 41$, latitude $=$ 7.7976216, longitude $=110.4184385$, dengan selisih waktu dikirim dengan waktu diterima sebesar 11 detik.

b) Baris ke 2 Drone Syma X8HG diterbangkan dengan ketinggian sekitar 2 meter diatas permukaan tanah yang mempunyai data yaitu waktu dikirim $=11: 28: 51$, waktu diterima $=11: 29: 02$, latitude $=$ 7.7976218 , longitude $=110.4184389$, dengan selisih waktu dikirim dengan waktu diterima sebesar 11 detik.

c) Baris ke 3 Drone Syma X8HG diterbangkan dengan ketinggian sekitar 4 meter diatas permukaan tanah yang mempunyai data yaitu waktu dikirim $=11: 29: 39$, waktu diterima $=11: 29: 50$, latitude $=$ 7.7976211 , longitude $=110.4184384$, dengan selisih waktu dikirim dengan waktu diterima sebesar 11 detik.

Dilihat dari Tabel 1 baris ke 1, dan baris 2 titik koordinat lokasi atau lalitude dan longitude ada sedikit perubahan dikarenakan Drone Syma X8HG terbang dengan ketinggian yang tidak terlalu tinggi antara 1 meter, 2 meter dan masih setabil, sedangkan pada Tabel 1 baris ke 3 titik koordinat lokasi sudah mulai mengalami perubah dikarenakan Drone Syma X8HG terbang sudah tinggi dengan ketinggian 4 meter dan Drone Syma X8HG terbang sudah tidak setabil dikarenakan terbawa oleh tekanan udara, untuk lebih jelasnya bisa dilihat pada Gambar 6.

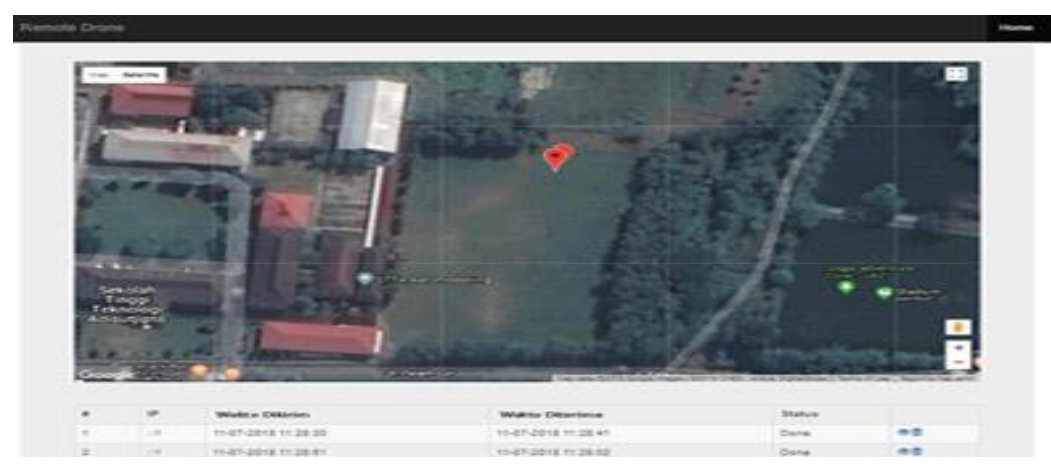

Gambar 6. Koordinat Lokasi Drone Syma X8HG Terbang Vertikal

Pengujian Drone Syma X8HG saat Terbang Horizontal dilakukan dengan cara menerbangkan Drone Syma X8HG secara horizontal dengan ketinggian 1 meter, 2 meter, dan diatas 2 meter hal ini dilakukan untuk mendapatkan data perubahan latitude dan longitude. Hasil dari pengujian ini dapat dilihat pada Tabel 2.

Tabel 2 Drone Syma X8HG saat Terbang Horizontal

\begin{tabular}{llllll}
\hline No & Ketinggian & Waktu dikirim & Waktu diterima & Latitude & \multicolumn{1}{c}{ Longitude } \\
\hline 1 & 1 meter & $10: 42: 55$ & $10: 43: 09$ & -7.7975756 & 110.418394 \\
2 & 1 meter & $10: 43: 25$ & $10: 43: 39$ & -7.7976039 & 110.4184073 \\
3 & 1 meter & $10: 43: 33$ & $10: 43: 46$ & -7.7976112 & 110.4184077 \\
4 & 1 meter & $10: 43: 44$ & $10: 43: 57$ & -7.7976218 & 110.4184004 \\
5 & 1 meter & $10: 43: 50$ & $10: 44: 03$ & -7.7976191 & 110.4184162 \\
6 & 1 meter & $10: 43: 56$ & $10: 44: 09$ & -7.797613 & 110.4184225 \\
7 & 1 meter & $10: 44: 01$ & $10: 44: 14$ & -7.7976159 & 110.4184235 \\
8 & 1 meter & $10: 44: 06$ & $10: 44: 19$ & -7.7976171 & 110.4184244 \\
9 & 1 meter & $10: 44: 09$ & $10: 44: 22$ & -7.7976151 & 110.4184234 \\
10 & 1 meter & $10: 44: 49$ & $10: 45: 03$ & -7.7976046 & 110.418413 \\
11 & 2 meter & $10: 44: 54$ & $10: 45: 08$ & -7.797602 & 110.4184028 \\
12 & 2 meter & $10: 45: 03$ & $10: 45: 16$ & -7.7975957 & 110.4183813 \\
13 & 2 meter & $10: 45: 07$ & $10: 45: 20$ & -7.7975968 & 110.4183853 \\
14 & 2 meter & $10: 45: 09$ & $10: 45: 23$ & -7.7975951 & 110.4183889 \\
15 & 2 meter & $10: 45: 12$ & $10: 45: 26$ & -7.7975941 & 110.4183971 \\
16 & 2 meter & $10: 45: 16$ & $10: 45: 29$ & -7.7975912 & 110.4184021 \\
17 & 2 meter & $10: 45: 21$ & $10: 45: 34$ & -7.7975891 & 110.418403 \\
18 & 2 meter & $10: 45: 23$ & $10: 45: 36$ & -7.7975889 & 110.4184031 \\
19 & 2 meter & $10: 45: 35$ & $10: 45: 48$ & -7.7976064 & 110.4184055 \\
\hline
\end{tabular}




\begin{tabular}{llllll}
\hline No & Ketinggian & Waktu dikirim & Waktu diterima & Latitude & \multicolumn{1}{c}{ Longitude } \\
\hline 20 & 2 meter & $10: 45: 38$ & $10: 45: 51$ & -7.7976051 & 110.4183994 \\
21 & 3 meter & $10: 45: 42$ & $10: 45: 55$ & -7.7976085 & 110.418404 \\
22 & 3 meter & $10: 45: 44$ & $10: 45: 57$ & -7.79761 & 110.4184074 \\
23 & 3 meter & $10: 45: 47$ & $10: 46: 00$ & -7.7976133 & 110.418409 \\
24 & 3 meter & $10: 45: 50$ & $10: 46: 02$ & -7.7976142 & 110.4184166 \\
25 & 3 meter & $10: 45: 53$ & $10: 46: 05$ & -7.7976121 & 110.4184109 \\
26 & 3 meter & $10: 45: 57$ & $10: 46: 11$ & -7.7976074 & 110.4184025 \\
27 & 3 meter & $10: 46: 00$ & $10: 46: 13$ & -7.7976087 & 110.4183985 \\
28 & 3 meter & $10: 46: 03$ & $10: 46: 16$ & -7.7976048 & 110.4184041 \\
29 & 3 meter & $11: 01: 27$ & $11: 01: 40$ & -7.797348 & 110.4184748 \\
30 & 3 meter & $11: 01: 35$ & $11: 01: 48$ & -7.7973492 & 110.4184753 \\
\hline
\end{tabular}

Pembahasan pada Tabel 2 yaitu Drone Syma X8HG diterbangkan secara horizontal dengan ketinggian 1 meter, 2 meter, dan 3 meter dengan jarak yang berbeda-beda untuk mendapatkan koordinat latitude dan longitude lebih jelasnya bisa dilihat pada keterangan dibawah ini:

a) Pada Tabel 2 baris ke 1 sampai dengan baris ke 10 Drone Syma X8HG diterbangkan horizontal memutar dengan ketinggian sekitar 1 meter dengan jarak sekitar 2 meter dari titik koordinat awal, memiliki data yaitu $:$ waktu dikirim $=10: 42: 55$, waktu diterima $=10: 43: 09$, latitude $=-7.7975756$, longitude $=110.418394$.

b) Pada Tabel 4.2 baris ke 11 sampai dengan baris ke 20 Drone Syma X8HG diterbangkan horizontal memutar dengan ketinggian sekitar 2 meter dengan jarak sekitar 2 meter dari titik koordinat awal, memiliki data yaitu : waktu dikirim $=10: 44: 54$, waktu diterima $=10: 45: 08$, latitude $=-7.797602$, longitude $=110.4184028$, selisih waktu dikirim dengan waktu diterima sebesar 14 detik.

\section{KESIMPULAN}

Smartphone yang diterbangkan oleh Drone Syma X8HG berhasil mengirimkan data latitude dan longitude melalui jaringan internet ke laptop yang telah dipasang perangkat lunak berbasis web dengan waktu yang dibutuhkan untuk mengirimkan data koordinat lokasi dari smartphone ke komputer dipengaruhi oleh kekuatan sinyal yang disediakan oleh provider, bukan dari tinggi rendahnya drone atau jauh dekatnya drone dari software. Data yang dikirimkan dari smartphone dapat diintegrasikan degan google map yang ada pada komputer yang digunakan untuk menerima data. Track jalur dapat dilakukan dengan dengan cara memasukan data koordinat latitude dan longitude yang ada pada tabel database ke google maps.

\section{DAFTAR PUSTAKA}

[1] Wintolo, H., Sudaryanto, S., \& Pramudito, C. G. 2018. "Remote Camera For Android Based Smartphones Installed On The Syma X8HG Drone". Angkasa: Jurnal Ilmiah Bidang Teknologi, 10(2), 130-140.

[2] Zulkarnain, T., Susanto, E., \& Wibowo, A. S.2016. "Perancangan Dan Implementasi Autonomous Quadcopter Dengan Kemampuan Follow Me Yang Terintegrasi Pada Android”. eProceedings of Engineering, 3(2).

[3] Wibowo, T. 2013. "Alat Pemantau Kendaraan Berbasis Gps Dengan Fitur Lokal Dan Sms Pintar". In Conference SENATIK STT Adisutjipto Yogyakarta (Vol. 1, pp. 25-36).

[4] Addiwinoto, G., \& Nugraheny, D. 2012. "Pemanfaatan Direction Api (Application Programming Interface) Pada Layanan Google Map Untuk Pencarian Rumah Ibadah Di Kotamadya Yogyakarta Pada Handphone Berbasis Android". Compiler, 1(2).

[5] Nurahmanto, H., Sumarsono, S., \& Suhayati, M. 2013. "Sistem Pencarian Lokasi Anjungan Tunai Mandiri (ATM) Memanfaatkan Google Map Untuk Handphone Android Yang memiliki Fasilitas Global Positioning System (GPS) Studi Kasus BPD DIY”. Compiler, 2(1).

[6] Saefudin, M. S., \& Julisawat, E. A. 2017. "Aplikasi Informasi Pariwisata Tempat, Budaya, Kerajinan Dan Kuliner Daerah Cirebon Berbasis Android”. Simetris: Jurnal Teknik Mesin, Elektro dan Ilmu Komputer, 8(1), 35-44.

[7] Utomo, A. P., Nugraha, F., \& Setiawan, A. 2014. "Pemetaan Industri Bordir Di Kabupaten Kudus Berbasis Sistem Informasi Geografis Menggunakan Google Map Api”. Simetris: Jurnal Teknik Mesin, Elektro dan Ilmu Komputer, 5(2), 161-166. 